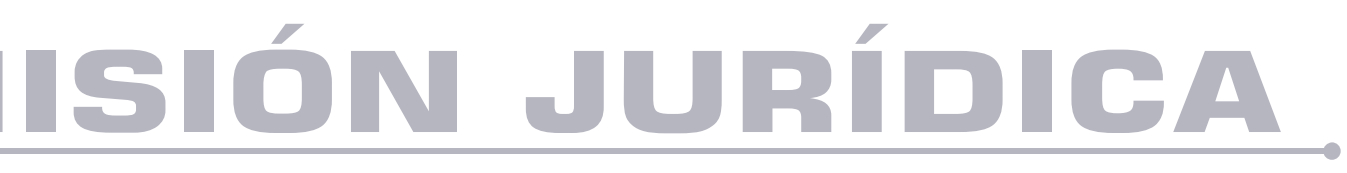

\title{
Análisis del derecho humano a la vivienda en México: en aras de un nuevo paradigma
}

An analysis of the human right to housing in Mexico: in pursuit of a new paradigm

Autores: Adrián Joaquín Miranda Camarena, Samantha Maldonado Ramos DOl: https://doi.org/10.25058/1794600X.1911

\footnotetext{
SP MISIÓN JURÍDICA A 


\title{
ANÁLISIS DEL DERECHO HUMANO A LA VIVIENDA EN MÉXICO: EN ARAS DE UN NUEVO PARADIGMA*
}

\author{
An analysis of the human right to housing in Mexico: in pursuit \\ of a new paradigm
}

Análise do direito humano à moradia no México: em prol de um novo paradigma

\author{
Adrián Joaquín Miranda Camarena ${ }^{a}$ \\ ajmiranda23@hotmail.com \\ Samantha Maldonado Ramos ${ }^{\text {b }}$ \\ s.samsam.sm@gmail.com
}

Fecha de recepción: 1 de octubre de 2020

Fecha de revisión: 12 de octubre de 2020

Fecha de aceptación: 27 de noviembre de 2020

DOI: https://doi.org/10.25058/1794600X.1911

Para citar este artículo:

Miranda Camarena, A.J y Maldonado Ramos, S. (2021). Análisis del derecho

humano a la vivienda en México: en aras de un nuevo paradigma. Revista

Misión Jurídica, 14, (20), 120-141.

\section{RESUMEN}

En México los derechos humanos son un tema muy agraviado, cuya directriz se ha frustrado debido a la aplicación que realizan las instituciones encargadas de su tutela. En el presente artículo el derecho humano a la vivienda digna y decorosa es sujeto de investigación como derecho humano y social, analizándolo mediante un recorrido desde su primera concepción, pasando por su evolución teórica, los mecanismos de protección y su justiciabilidad, así como su estado actual; por medio

\footnotetext{
* El presente artículo de reflexión es realizado bajo un esquema de trabajo de investigación en posgrado, previo interés común entre los suscritos por el tema es que surge la determinación de desprender este análisis del derecho a la vivienda. Así bien, como prioridad la aportación al estudio e investigación en materia de derechos humanos es primordial tanto para la función personal como laboral en un estado de derecho mayormente vulnerado en México.

a. Abogado egresado de la Benemérita Universidad de Guadalajara, Profesor Investigador adscrito al Centro Universitario de Ciencias Sociales y Humanidades de la Universidad de Guadalajara, con estudios de Maestría en Derecho Constitucional y Amparo por parte de esta. Especialidad en Derecho Constitucional y Ciencia Política otorgada por el Centro de Estudios Políticos y Constitucionales del Ministerio de la Presidencia Española. Estudios Avanzados en Derecho Constitucional y Doctor en Derecho por parte de la Universidad Carlos III de Madrid. Maestro en Derecho Electoral por el Instituto Prisciliano Sánchez del Tribunal del Poder Judicial del Estado de Jalisco y Doctor en Derecho Electoral por la Universidad de Pisa, Italia, actualmente Magistrado del Tribunal de Justicia Administrativa del Estado de Jalisco.
}

b. Abogada egresada por la Benemérita Universidad de Guadalajara, maestrando en Derecho Constitucional y Administrativo por parte del Centro Universitario de Ciencias Sociales y Humanidades de la Universidad de Guadalajara. 
de un diseño empírico de su situación es que se ha de evidenciar como este derecho social ha sido olvidado en todos los aspectos que lo constituyen en su compleja conformación. La concepción de la vivienda como un derecho social ha evolucionado $\mathrm{y}$ es urgente tomar decisiones que se adecuen al nuevo paradigma en el que se encuentra actualmente inactivo en cuanto a estudio y acción.

\section{PALABRAS CLAVES}

Derechos humanos; vivienda digna; derecho social; justiciabilidad; paradigma; México..

\section{ABSTRACT}

In Mexico, human rights are a very neglected subject, and its guideline has been frustrated due to the way it is applied by the institutions in charge of their protection. In this article, the right to decent and dignified housing is the subject of research as a human and social right, analyzing it through a journey from its first conception, its theoretical evolution, its application and justiciability mechanisms, as well as its current status, by an empirical design of its situation in Mexico. This makes necessary to show how this social right has been the target of oblivion in all the aspects that constitute its complex conformation. The conception of housing as a social right has evolved and it is urgent to make decisions that adapt to the new paradigm in which is currently inactive in terms of study and action.

\section{KEY WORDS}

Human rights; decent housing; social right; justiciability; Mexico; paradigm.

\section{RESUMO}

No México, os direitos humanos são uma questão muito prejudicada, cuja diretriz foi frustrada pela aplicação realizada pelas instituições encarregadas de sua proteção. Neste artigo, o direito humano à moradia digna e digna é objeto de investigação como direito humano e social, analisando-o através de um percurso desde a sua primeira concepção, passando pela sua evolução teórica, os mecanismos de proteção e sua justiciabilidade, bem como a sua status atual; Por meio de um desenho empírico de sua situação, devese mostrar como esse direito social foi esquecido em todos os aspectos que o constituem em sua complexa conformação. A concepção da habitação como direito social evoluiu e é urgente tomar decisões que se adaptem ao novo paradigma em que se encontra inactiva ao nível do estudo e da acção.

\section{PALAVRAS-CHAVES}

Direitos humanos; habitação decente; direito social; justiciabilidade; paradigma; México.

\section{INTRODUCCIÓN}

La trascendencia del derecho a la vivienda es muy importante en la vida y la dignidad de los seres humanos, desde su individualidad hasta su presencia en sociedad, sin embargo, es uno de los derechos con menor atención en el ámbito de estudio. En el presente artículo, se pretende exponer un análisis de los diversos mecanismos utilizados por el Estado para garantizar y proteger el derecho humano a la vivienda, al igual que confrontar la eficacia que estos mecanismos ejercen frente a la realidad del bienestar humano. Tanto los mecanismos de protección existentes en esta materia, así como las instituciones que recogen el deber de garantizarlo y llevar a cabo su ejercicio son insuficientes, aunado a ello, las interpretaciones de la noción de la vivienda en el estado mexicano carecen de un valor significativo en la praxis y la falta de sanciones a los reiterados yerros de la administración, conforman un malogrado estado de derecho.

La contribución a la obra científica actual en materia de vivienda es prioridad en este título, toda vez, que a lo largo de la historia de los derechos humanos y los derechos sociales la vivienda contiene una complejidad que está en constante y reiterado cambio, por lo que la actualización y comparación que se utilizan en el desarrollo de este artículo exploran dos mundos, "el deber ser" enfrentado a "la realidad."

¿El Estado mexicano garantiza el derecho humano a la vivienda digna y decorosa? La composición del derecho a la vivienda implica una armonía de varios elementos, debe erradicarse la idea de una vivienda digna y decorosa como una "casa más o menos grande", la noción que se pretende trasmitir en este proceso intelectual va más allá. Bajo la contemplación del marco normativo nacional e internacional se han de conocer los alcances adquiridos en materia de vivienda, así como los objetivos de cumplimiento que el Estado debe constituir para medir la eficacia en la aplicación de este derecho. También, 
mediante la distinción que tiene el derecho a la vivienda como derecho humano y como derecho social, se procura un entendimiento más amplio de su concepto, sus características y los medios de protección jurídica con que cuenta.

Se confrontará la realidad en los diversos campos de acción y estudio de la vivienda, desde su naturaleza como derecho social hasta su transformación e interpretación actual, una vez que se logre la percepción de lo anterior, por medio de un análisis conveniente e indagando en sus mecanismos y la implementación que se lleva a cabo de estos, se logrará la visión de las lagunas que merman el derecho a la vivienda en México y el desgaste que este ha padecido a lo largo del tiempo; sin embargo, también han de señalarse las fortalezas que pueden ser herramientas de trabajo pertinentes en las acciones del Estado.

\section{NATURALEZA DE LOS DERECHOS SOCIALES}

El derecho humano a una vivienda digna y decorosa es un derecho de carácter social, los derechos sociales, nacen como aspiración de la sociedad, un ideal de lo que pretende alcanzar el ser humano y asistir a su dignidad. Sus características han tenido a lo largo de los años diversas dimensiones, en cuanto a su concepto y tratamiento. Esta aspiración es plasmada en México desde la Constitución de 1917, con la entrada de los derechos sociales en el marco normativo. Es su nacimiento lo que los sitúa en una posición diferente a la actualidad, los derechos sociales nacen como demandas del pueblo al Estado, resultado de luchas políticas y sociales para lograr cierto status legal de algunos grupos particulares, tal como lo es el derecho a una vivienda. La imposición al Estado de otorgar un apoyo, ayuda o asistencia a determinados grupos en desventaja, fue el objeto de sus inicios; en particular, la vivienda surge como un pedimento de los trabajadores hacia los patrones de otorgarles un alojamiento higiénico, que sea digno para fortalecer los derechos laborales e intenciones del régimen político de la época. Por tanto, esta dicotomía del derecho a la vivienda en su origen, ha de discernirse con el tiempo, desde su categoría como derecho humano hasta su individualidad, para enfrentar un nuevo paradigma.

Los derechos sociales no pueden ser comprendidos desde sus propios elementos, éstos deben observarse desde una perspectiva que proviene de los documentos que los atañen, hasta el propio régimen en el que fueron concebidos. Existe una gran diversidad de conceptos que se le han otorgado a los derechos sociales, desde ser considerados como una simple programación del Estado, hasta una importancia encarnada para los regímenes democráticos. Para efectos del presente artículo se ha de determinar una postura frente a los Derechos, Económicos, Sociales y Culturales (DESC) y para fortalecer el entendimiento de su implementación en el mundo jurídico, ha de ponerse en evidencia su naturaleza, como bien lo menciona el párrafo anterior, el origen de los derechos sociales es de suma importancia para su interpretación.

El fenómeno de los Derechos Económicos, Sociales y Culturales sin lugar a duda fue resultado de luchas sociales que pretendieron poner fin a eras de desigualdad social, abusos y limitaciones, así como enaltecer la dignidad para mejorar la existencia del ser humano, jugando a la par de los llamados derechos naturales del hombre. Como concepto de derechos sociales nos dice el jurista colombiano Arango Rivadeneira, que son aquellos "derechos subjetivos de prestación positiva fáctica del Estado" (2015, p. 1683) , ésta definición suele repetirse en múltiples autores, de acuerdo a esta posición, la característica sobresaliente es la "prestación positiva", es decir, la limitación a obligaciones de hacer por parte del Estado, por lo que consecuentemente y a diferencia de otros derechos, se requiere realizar acciones y para cubrirlas es precisa la utilización de recursos públicos destinados a ello; es decir, brindar prestaciones positivas, implica un cumplimiento de actuaciones previstas en el sistema jurídico que advierten un coste, verbigracia para garantizar el derecho a la vivienda se requieren acciones por parte del Estado para brindar infraestructuras, modalidades de créditos, servicios básicos, etcétera, para que todas las familias puedan gozar de este derecho; en cambio, cuando se trata de obligaciones negativas por parte del Estado, este no tiene obligación de acción, por ejemplo, sobre la libertad de expresión y la libertad de asociación, la obligación es no restringir, otro ejemplo, no aplicar penas sin juicio previo; el objeto de la obligación resulta interesante si se realiza un análisis con detenimiento respecto a los derechos sociales, la actuación del Estado en los derechos sociales puede ser también de índole negativa, no en absoluto positiva. 
Bajo el ejemplo de la vivienda, que es el caso que nos ocupa, el Estado una vez que otorga este derecho, debe conformar su prestación positiva, $\mathrm{y}$ conforme a lo mencionado, sus acciones consistirían, entre otras, en crear instituciones que efectúen lo necesario para su cumplimiento, así como, distribuir los servicios básicos necesarios en las viviendas, atender la planeación urbana, adecuar espacios para la habitabilidad de los mismos y alrededores, etcétera; sin embargo, también bajo el objeto de prestación negativa, está obligado a no afectar la vivienda, a impedir su daño, a no permitir espacios donde no se conduzca una adecuada habitabilidad, evitar desalojos forzosos, etcétera; en consecuencia, los derechos sociales, no solo son de prestación positiva, sino que conllevan obligaciones negativas del Estado para la aplicación y el cumplimiento en su totalidad, asimismo se podría concluir que solo es una diferencia de grado frente a otros derechos. Tomando en cuenta que en las prestaciones de hacer, se requieren recursos destinados a estas acciones, se podría decir que también para las acciones negativas, se comprometen recursos.

Señala el autor Melo, que "para los derechos sociales, la prestación estatal representa verdaderamente la sustancia, el núcleo, el contenido esencial del derecho" (2014, p. 292) las obligaciones del Estado son básicas para entender los derechos sociales, y en efecto, la prestación estatal de éstos, está conformada mayormente por prestaciones positivas, y sí, conmina al Estado a tener mayor compromiso como eje rector del camino a la tutela del mismo derecho; la intervención del estado tiene lugar en todas y cada una de las veces que el derecho se ejercita; la inexistencia de prestación estatal supone automáticamente la denegación del derecho (como se cita en Melo , 2014, p.. 292) esto resulta muy importante toda vez que, revela la importancia de las acciones del Estado, en el caso de los derechos sociales en particular, es decir, no bastarían las obligaciones de no hacer del Estado, eso supondría una vulnerabilidad del derecho, por lo que podemos deducir que la obligación de no hacer u omisión dentro de los derechos sociales, es solo en cuanto a la no realización de actos destinados a la afectación de los elementos que conforman el derecho en particular, en el presente caso, el derecho a la vivienda. Resultando entonces que la particularidad con la que son tratados los derechos sociales en cuanto a ser de prestación positiva fáctica del estado, no es absoluta, los derechos sociales también contienen sus abstenciones y posiciones negativas.

Abramovich y Courtis señalan que "muchas de las acciones legales tendientes a la aplicación judicial de los derechos económicos, sociales y culturales se dirigen a corregir la actividad estatal cuando ésta incumple con obligaciones de no hacer" (1977, p. 4). Aunque las prestaciones positivas sean las que distingan y conforman mayoritariamente a los derechos sociales, también existen prestaciones negativas en su estructura que son de vital interés, estos autores, señalan que lo más vulnerado por el Estado son esas prestaciones que en menor cantidad conforman los derechos sociales. De hecho, la afectación y el resultado, como consecuencia de las abstenciones y obligaciones de no hacer del Estado, son las que mayormente se consideraran y se adaptan para asistir a reclamar ante los órganos competentes, porque de la manera que sea, los derechos sociales establecen una protección para sí, mediante ciertos mecanismos; en relación a lo anterior, es oportuno lo que Cruz (2017) expresa:... los derechos sociales no se concibieron en ningún momento como genuinos derechos que pudieran ser reclamados frente a Jueces y tribunales. Su forma de protección consistió en un entramado institucional y corporativo, que dio lugar a un clientelismo político que sujetaba y condicionaba la acción y la lucha social ( p. 39).

Claro está que no podemos separar la creación de los derechos económicos, sociales y culturales, de una utopía mal pensada, Cruz Parcero mediante un análisis jurídico, aterriza en la concepción de los derechos sociales como un reconocimiento para los individuos, más no figuras de mecanismos de protección y seguridad jurídica; es decir, son derechos que si no se cumplen, no pasa nada; los derechos sociales tienen la reputación de no contar con protección jurídica alguna, y esto no es nuevo, del simple análisis de los instrumentos internacionales respecto a derechos humanos, se puede observar en un documento, los derechos civiles y políticos, y en otro creado más tarde, los derechos sociales, económicos, culturales y ambientales, las desigualdades que se encuentran en los contenidos, logran manifestar cierta distinción respecto al grado de obligatoriedad 
de cómo deben ser tratados; en el instrumento internacional "Pacto Internacional de Derechos, Económicos, Sociales y Culturales", se señala claramente, respecto a su cumplimiento, lo siguiente:

\section{Artículo 2}

1. Cada uno de los Estados Partes en el presente Pacto se compromete a adoptar medidas, tanto por separado como mediante la asistencia y la cooperación internacionales, especialmente económicas y técnicas, hasta el máximo de los recursos de que disponga, para lograr progresivamente, por todos los medios apropiados, inclusive en particular la adopción de medidas legislativas, la plena efectividad de los derechos aquí reconocidos.

2. Los Estados Partes en el presente Pacto se comprometen a garantizar el ejercicio de los derechos que en él se enuncian, sin discriminación alguna por motivos de raza, color, sexo, idioma, religión, opinión política o de otra índole, origen nacional o social, posición económica, nacimiento o cualquier otra condición social.

3. Los países en desarrollo, teniendo debidamente en cuenta los derechos humanos y su economía nacional, podrán determinar en qué medida garantizarán los derechos económicos reconocidos en el presente Pacto a personas que no sean nacionales suyos (Organización de las Naciones Unidas - ONU, 1996).

El artículo señalado compromete a los Estados parte del Pacto a adoptar medidas de acuerdo al máximo de recursos con que disponga, además, no manifiesta una obligación expresa a todos los países parte del Pacto a garantizar por igual los derechos sociales, sino que depende del nivel de desarrollo que cada país o sociedad tenga, además señala que la adopción de estas medidas serán dentro de lo posible, sin mencionar acción judicial alguna en contra de la violación de los mismos, a diferencia del Pacto Internacional de Derechos Civiles y Políticos que en el apartado equivalente señala a la letra, lo siguiente:

\section{Artículo 2}

1. Cada uno de los Estados Partes en el presente Pacto se compromete a respetar $\mathrm{y}$ a garantizar a todos los individuos que se encuentren en su territorio y estén sujetos a su jurisdicción los derechos reconocidos en el presente Pacto, sin distinción alguna de raza, color, sexo, idioma, religión, opinión política o de otra índole, origen nacional o social, posición económica, nacimiento o cualquier otra condición social.

2. Cada Estado Parte se compromete a adoptar, con arreglo a sus procedimientos constitucionales y a las disposiciones del presente Pacto, las medidas oportunas para dictar las disposiciones legislativas o de otro carácter que fueren necesarias para hacer efectivos los derechos reconocidos en el presente Pacto y que no estuviesen ya garantizados por disposiciones legislativas 0 de otro carácter.

3. Cada uno de los Estados Partes en el presente Pacto se compromete a garantizar que:

a) Toda persona cuyos derechos o libertades reconocidos en el presente Pacto hayan sido violados podrá interponer un recurso efectivo, aun cuando tal violación hubiera sido cometida por personas que actuaban en ejercicio de sus funciones oficiales;

b) La autoridad competente, judicial, administrativa o legislativa, o cualquiera otra autoridad competente prevista por el sistema legal del Estado, decidirá sobre los derechos de toda persona que interponga tal recurso, y desarrollará las posibilidades de recurso judicial;

c) Las autoridades competentes cumplirán toda decisión en que se haya estimado procedente el recurso (ONU, 1966).

Se puede observar de lo anterior, que en el punto tres del artículo segundo de este Pacto, se precisa la manera de hacer justiciables y exigibles lo contenido en este documento, comprometiendo a los Estados parte del mismo a adoptar las medidas necesarias, sin depender del grado de desarrollo de su sociedad, es decir es una obligación asignada a garantizar estos derechos sin excusa, esta distinción de garantía entre uno y otro grupo de derechos, robustecen la teoría de que los derechos sociales, no tienen un valor legítimo, sino que sólo son metas, objetivos que se buscan alcanzar conforme lo posiblemente utilizable en cada territorio.

La UNESCO en su portal manifiesta que "los derechos económicos, sociales y culturales se 
han considerado durante mucho tiempo como 'derechos secundarios' comparado con los derechos civiles y políticos" (n. d), este es un problema que los Derechos Económicos, Sociales, Culturales y Ambientales han tenido desde el inicio de su existencia; por ejemplo, en el caso que nos ocupa, el derecho de vivienda, al ser en su origen un derecho prestacional por parte del Estado a ciertos sectores de privilegio como lo es el sector asalariado, o de los trabajadores, se puede tender a pensar que el principio de igualdad no está totalmente resguardado con este derecho y las clases sociales aún con los derechos reconocidos en la Carta Magna eran marcadas por una tendencia a beneficiar mayormente a una parte de la población; asimismo, a la evolución del tiempo, tras modificaciones de la Constitución y la pretensión de un estado de bienestar para todas las familias, se ubica en un plano de igualdad que se inclina a un panorama casi imposible y es entonces, cuando su consumación no se espera de manera inmediata, surgiendo la problemática que versa en si es posible. por parte del Estado brindar vivienda digna y decorosa para todos, aún con su máximo esfuerzo. Si bien, en la evolución y a lo largo del tiempo se implementan los derechos sociales como derechos humanos fundamentales para todo ser humano sin distinción, ha de entenderse que existan vacíos dentro de sus manifiestos, o tal vez poco análisis, que encaminen a una verdadera concepción de lo que son los derechos sociales. Este modelo de aspiración de los derechos sociales, los dota de la característica de ser una meta para el Estado, es decir, son derechos programáticos. ¿Cómo manejan su garantía los derechos programáticos?

En México la concepción de los derechos sociales ha cambiado conforme su historia y ha sido un escenario de debate, donde la interpretación de derechos sociales como aspiraciones, ha sido superior. Para Cruz (2017) el origen de los derechos sociales:

...estuvo ligado a un régimen presidencial, patrimonialista, corporativista, clientelar y antidemocrático que se consolidaría después de promulgada la Constitución de Querétaro. Los derechos sociales -para ser más preciso, el contenido social de la Constituciónsirvieron para legitimar un régimen político que no apostó por la legitimidad democrática (p. 46).
De lo anterior, cabe destacar del autor que de manera negativa ha de tratarse el origen de los derechos sociales en el régimen político mexicano, señalando que nacen como una utopía que se ha pretendido instituir y no se ha logrado con los fines democráticos. En la práctica las diferentes clasificaciones de los derechos económicos sociales y culturales se han desarrollado de manera distinta, debido a la múltiple comprensión de las obligaciones que tiene el Estado respecto a estos derechos. "...los derechos sociales reconocidos en el ordenamiento jurídico no son verdaderos derechos, cuya defensa, ejercicio y disfrute corresponden a su titular, en cuanto sujeto de derecho, sino que son principios programáticos meramente directivos y ordenadores de la acción política del Estado" (Vicente, 2006, p. 96). Esta concepción de los derechos sociales, al igual que la idea de Cruz pretende conjeturar que el titular del derecho no tiene el poder reconocido de dirigirse a un procedimiento para buscar la justicia, disponiendo y estando sometidos completamente a voluntades políticas, así como que el Estado no tiene una total obligación de cumplir con estos derechos, aún incorporados en la legislación. En esta definición de Vicente los precisa como programáticos, como principios a seguir, guía del Estado, a sabiendas que como principios no manejan entonces obligatoriedad alguna de cumplirse inmediatamente.

Previo a analizar el término de la palabra "programático" y es el objetivo con lo que se está trabajando, una pauta para entender a los derechos sociales como derechos programáticos podría iniciar y comprenderse de la siguiente manera: en materia de vivienda, el 7 de febrero de 1983, se adicionó al artículo cuarto constitucional el derecho a la vivienda digna en un párrafo que a la letra dice: "Toda familia tiene derecho a disfrutar de vivienda digna y decorosa. La Ley establecerá los instrumentos y apoyos necesarios a fin de alcanzar tal objetivo" (Diario Oficial de la Federación).

Esta es la primera vez que se integró el derecho a la vivienda para todas las familias en la Constitución, lo que generaba entonces una obligación por parte del Estado, objeto de prestación positiva mayormente, tal como se aclaró anteriormente. Esta inclusión se acompañó de una ola de derechos más, que se fueron agregando en una época de crisis donde el estado mexicano se planteaba de diferentes frentes, los 
distintos modelos de sociedad y el rompimiento de la economía, exigieron cambios normativos y variadas soluciones, así se dieron reformas en materias diversas. De esta época de Estado de Bienestar, José Ramón Cossío Diaz dice:

Por un lado se reformó la Constitución con el fin de introducir "derechos" sociales de carácter prestacional, buscando con ello mantener vivo el ideario de la Revolución en momentos de crisis y, por el otro, se modificó la concepción de los propios derechos para hacerla jurídicamente inocua (p. 317).

Por lo que así como se planteaban las diversas reformas, agregando derechos por proporcionar una legitimación del Estado en cuanto a la situación vivida en aquella época y tiempos difíciles, era necesario que se llevara a cabo una implementación de los derechos sociales con un significado normativo, no solo de justificación respecto de la constitución, así entonces se fueron acuñando ideales respecto a los derechos sociales, y fue surgiendo la idea de una simple programación implementada en la Constitución para desarrollar a posterioridad; en un Congreso Nacional de Derecho Constitucional en 1983, Jorge Madrazo comentó sobre los derechos sociales que: "su naturaleza programática cabe, desde luego. Si su esencia programática supone una imposibilidad inmediata y automática, no se identifica en modo alguno con normas puramente teóricas o adjetivas". Esta afirmación y lo anterior, es base para el entendimiento del carácter programático de los derechos sociales, si bien, explica que tienden a ser un lineamiento a seguir, en algún punto del proceso han de llegar a ser ejecutados, desde luego que este ideal de lo programático tiene sentido, pero este también puede entenderse de manera negativa para el valor jurídico de estos derechos, porque al tenerse esta característica, entonces dentro de tales normas se pone en duda su real eficacia, o cómo se mide esa eficacia.

Crisafulli, jurista italiano, define las normas programáticas como:

las normas que, en vez de regular, desde el primer momento de modo directo e inmediato, determinadas situaciones $y$ relaciones (a las que se refieren), regulan comportamientos públicos destinados, a su vez, a incidir sobre dichas materias, es decir, establecen aquello que los gobernantes deberían o podrían hacer (e, inversamente, pues, aquello que no podrían hacer) relativa a los asuntos determinados (Citado en Da Silva, p. 104).

Esto reafirma lo que se ha venido trazando respecto de una regulación a futuro, donde no se regula de modo directo e inmediato y la elección de los medios es libre, se busca seguir en procura del cumplimiento por parte del Estado, pero ¿tiene la misma eficacia una norma programática?, ¿y hasta qué momento cumple su función programática?

Guissepe Lumia (1993) respecto de las normas programáticas explica que para que el Estado consiga el objetivo planteado en este tipo de norma, la discrecionalidad juega un papel muy importante en cuanto a la elección de los medios para atenderla. Este tipo de discrecionalidad puede consecuentemente afectar la eficacia de la norma.

Antes de ahondar en la eficacia de los derechos programáticos, cabe resaltar como el carácter de programático en los derechos sociales, modifica su valor frente a otros derechos, los derechos sociales sí son normas programáticas, porque nacieron de esa manera y en la actualidad no ha habido un desarrollo que modifique esta interpretación, los derechos sociales si bien cuentan con esta característica en teoría, en toda su conformación no son solo este tipo de normas las que imperan dentro de las acciones que realiza, es decir, para cumplir el derecho humano a la vivienda, es necesario cumplir con otro tipo de normas no programáticas para su cabal consumación, en todo caso, si existe una norma programática, en un momento de su existencia, ha de lograr dejar de serlo, por su consumación.

En este tenor, la teoría del Derecho refiere que "la eficacia de un sistema jurídico es condición necesaria de su existencia" (Hierro, 2003), esto quiere decir que si el sistema jurídico de un estado existe, es porque nació de una necesidad que implica ser debidamente cumplimentada, el fin de un sistema jurídico es esencialmente ser cumplido por las autoridades correspondientes a su aplicación; es decir, en el caso de los derechos sociales, la eficacia no puede ser mediata, según su carácter progresivo, depende mucho de las decisiones legislativas para implementar el 
derecho y que llegue a un nivel donde pueda ser materia de un procedimiento judicial. La eficacia de las normas tiene un fin en particular que consiste en llevar a la acción la intención total del legislador que crea la norma, este fin también es importante tanto que dentro de su conformación la interpretación de la misma es fundamental, la exposición de motivos de las leyes es una guía de lo que realmente el legislador ha tratado de decir dentro de la norma establecida, es de alguna forma lo que el legislador pretende establecer, controlar, modificar, etcétera, en la sociedad, éstas explicaciones pueden ser ciertas o no, pueden ser honestas o no, beneficiosas o no, lamentablemente no siempre el legislador tiene una buena intención dentro de la creación, modificación, derogación en su caso particular de las normas, pero aun así, si una norma es obligatoria es entonces cuando la interpretación recae en el sujeto obligado a cumplirla. Entonces, una norma es eficaz cuando es debidamente cumplida por el sujeto de la obligación, pero cuando la norma es programática, o bien contiene derechos de carácter programático, las acciones en grado menor o mayor, tienen el mismo valor para considerar su cumplimiento, toda vez que el principio de programático consiste en dirigir, al estar dentro de un ordenamiento su eficacia radica en ser un eje directivo, pero a la vez dentro del margen de ser una norma que contiene un derecho social a cumplir, para ese cumplimiento las normas no son programáticas sino que son de aplicación inmediata y precisa.

Pero en el caso que nos ocupa, los derechos sociales $i a$ quién recae esa obligación $y$ a qué obligan? Al ser derechos de prestaciones positivas y negativas del Estado, como lo vimos anteriormente, estas prestaciones, toda vez, que en ellas es necesaria la acción u omisión de la parte obligada, es entonces cuando se puede deducir que la obligación para su cumplimiento es del Estado; cuando es la autoridad quien ha de cumplir las normas se torna diferente a cuando el sujeto obligado es el gobernado, el cumplimiento se entiende como una forma de obedecer las reglas establecidas, o de actuar acorde las imposiciones instauradas. Es decir, el cumplimiento no es más que la adecuación de la conducta a la norma y tener plena conciencia de sí misma, por lo que el tipo de razonamiento con el cual se lleva a cabo la interpretación de las normas es básico para su entendimiento y su entonces cumplimiento y aplicación.
En este tenor, es importante analizar de la misma forma a quién van dirigidos los derechos sociales, para empezar, mucho se habla de grupos de personas específicos o a un sector específico. Para Cossío (2016) los tipos de creación de los derechos económicos, sociales y culturales mantienen esta dirección en los siguientes términos:

La idea de que tenemos dos tipos de derechos sociales en la Constitución mexicana puede ser cuestionada. El primer tipo estaría conformado con los contenidos en los artículos 27 y 123 constitucionales, que son derechos que no generan prestaciones materiales para el Estado mexicano, toda vez que regulan las relaciones de trabajo o las relaciones en el campo. En estos casos el Estado no realiza desembolsos económicos extraordinarios, sino que impone determinadas cargas a ciertos sectores sociales por considerarlos socialmente poderosos (2016, p. 134).

Esta diferenciación es común, enmarca un cuadro de desigualdad en cuanto a los sectores que van dirigidos con preferencia, en el caso que nos ocupa la vivienda en México, sí tuvo su origen en un sector determinado para beneficio del mismo, como derecho laboral otorgado, lo fue el sector asalariado, los trabajadores contaban con su derecho a una vivienda y disponían de apoyos conforme a lo establecido en la ley, pero en tanto, la evolución de la norma suprema y la teoría, se enganchó un nuevo paradigma que engloba ya no solo al sector trabajador, sino a todas las familias, y personas sujetas al Estado mexicano, por lo que ahora es una norma general y el derecho es otorgado a todos por igual y se incluye una prestación material para su cumplimiento.

El Estado es quien debe de dar cumplimiento a los derechos sociales, toda vez que tanto en la Constitución como en los Tratados Internacionales está esa obligación, y es aquí donde entra un elemento muy importante, un parteaguas, que crea un nuevo paradigma de los derechos sociales, en el año 2011 en México se reformó la Constitución Mexicana y se trató a "todos" los derechos humanos con las mismas características vinculantes y de una misma jerarquía. Por lo que los derechos sociales pasaron a obtener una exigibilidad y justiciabilidad, de la cual antes se tenía duda. 
Previo a esta reforma en México, en un ámbito internacional el Alto Comisionado de las Naciones Unidas dice, al respecto de los derechos sociales y la obligación del Estado y su efectividad, lo siguiente:

los Estados pueden dar efectividad de manera progresiva a los derechos económicos, sociales y culturales, también han de adoptar medidas de inmediato, independientemente de los recursos de que dispongan, en cinco esferas: eliminación de la discriminación; derechos económicos, sociales y culturales no sujetos al logro progresivo de la efectividad; obligación de "adoptar medidas"; prohibición de medidas regresivas; $\mathrm{y}$ obligaciones mínimas esenciales (ACNUDH, n. d., subrayado nuestro).

En primer término, respecto del análisis del cumplimiento del Estado, la característica de progresividad en los derechos sociales, es lo que aborda una complicación en su entendimiento, en el caso de la vivienda, del análisis de 50 años atrás destacamos que si un cierto sector ha de tener realizable este derecho, como lo es el de los trabajadores respecto del acceso, en la evolución conforme a su exigibilidad y justiciabilidad no se ha desarrollado al ciento por ciento, por lo que retomando el principio de progresividad señalado en párrafos anteriores, ha de verse afectado, tanto que podemos verificar ¿cómo se mide esa progresividad?, ¿cómo saber que en realidad hay un progreso constante en los derechos sociales?

El principio de progresividad de derechos humanos implica el gradual progreso para lograr su pleno cumplimiento, es decir, que para el cumplimiento de ciertos derechos se requiera la toma de medidas a corto, mediano y largo plazo, pero procediendo lo más expedita y eficazmente posible (Castañeda, 2016, pág. 11).

Este proceso gradual del que habla la autora, tiende a cumplirse en algún momento, por lo que bajo este esquema y aunado a un carácter programático, los derechos sociales sí tuvieron en un inicio esas características y sí estuvo en duda, en algún momento de su historia, su obligatoriedad, pero este principio es toral en su proceso, no puede haber una regresión en el avance de la implementación de estos derechos, como lo señala la Comisión Nacional de Derechos
Humanos, una vez que se disminuya ese nivel logrado se puede vulnerar el estado de derecho.

A manera de concluir lo anterior, con una postura frente a los derechos sociales, tras analizar las características que implican su cumplimiento, los sujetos de los derechos, las obligaciones y su tiempo; los derechos sociales son derechos subjetivos de prestaciones mayormente positivas, que forman parte fundamental del ser humano y de los derechos humanos, y no cabe la posibilidad de que sigan considerándose solo como programáticos, toda vez que en un inicio sí se identificaron así, hoy en día se tienen herramientas en el plano nacional e internacional que los hace factibles, bajo el principio de progresividad, estamos en ese futuro donde hace tiempo se consideraban realizables, si no es así, es porque las determinaciones para su cumplimiento han avanzado por un camino poco eficaz; sin embargo, los derechos sociales deben ser tutelados y lo han sido, conforme se adaptan a los sistemas jurídicos diversos, solo que ahora cobraron una fuerza a la par que todos los derechos humanos existentes.

El cambio de paradigma que requieren los derechos sociales y en específico el derecho a la vivienda, no solo debe de ser percibido por parte del Estado, sino también del ente gobernado que debe conocer sus mecanismos de defensa, obtención y control para lograr la correcta aplicación y disfrute de los mismos; la diferencia del momento en que surgieron y se implementaron los derechos sociales, a la actualidad, es que se tienen años de ventaja para analizar los errores que se han contenido y a base de eso y de la mano con las nuevas herramientas, dar un giro y realizar una tutela efectiva que garantice el Estado de Derecho.

Con el carácter de social, programático y progresivo el derecho a la vivienda no debe estancarse en un modelo que promete a futuro su realización, debe de aplicarse y ejercerse día con día las acciones necesarias a la implementación íntegra en el estado mexicano, toda vez que este derecho se nivela de la misma forma que los derechos humanos fundamentales.

Nota: Revisar que se pasa del ítem 1 al ítem 3, si falta el ítem 2 o no 


\section{UN NUEVO CONTROL}

La tutela efectiva de los derechos humanos no se garantiza por estar en el papel o tener una clasificación en generaciones, las acciones y omisiones del garantista son muy importantes, el desconocimiento por parte de las personas que gozan de estos derechos no reduce la responsabilidad de efectuarlos adecuadamente, lamentablemente la falta de información, interés, divulgación y el acceso a mecanismos que garanticen los derechos humanos es un problema que aún afecta países en el mundo. La vivienda en su evolución logra establecer su igualdad y adquiere herramientas jurídicas importantes con el paso del tiempo y los grandes cambios en la población mundial.

El gran cambio que hubo en México en 2011, cuando se marca un parteaguas en materia de derechos humanos y por lo tanto en materia de derechos sociales, por medio de una reforma que concede a todos los individuos el goce de los derechos humanos contenidos en la Constitución y en todos los Tratados Internacionales en los que México participe, entonces los derechos sociales al ser parte de estos instrumentos, se vuelven obligatorios en todo el sistema mexicano. Aquí, a esta altura es posible identificar que los derechos sociales dan un giro que es imposible de ignorar en el ámbito jurídico. En cuanto al dilema de la exigibilidad y justiciabilidad de los derechos sociales, es preciso mencionar que esta reforma acarreó una imposición que venían necesitando desde años atrás, cambiando la manera de ver a los derechos en general y dotando a cada uno de características y principios iguales, que no pueden ponerse en duda, o bien para ciertos efectos académicos, pero lo establecido en la Constitución en el año 2011, precisó las obligaciones del Estado y la evolución de un México dañado.

El artículo primero de la Constitución mexicana previo a la reforma establecía: “[...] en los estados unidos mexicanos todo individuo gozará de las garantías que otorga esta Constitución, las cuales no podrán restringirse ni suspenderse, sino en los casos y con las condiciones que ella misma establece. [...]" (Constitución Política de los Estados Unidos Mexicanos, DOF 05-02-17.)

El texto actual reformado ese año en la Constitución Política de los Estados Unidos Mexicanos, establece ahora que "todas las personas gozarán de los derechos humanos reconocidos en esta Constitución y en los Tratados Internacionales de los que el Estado mexicano sea parte, así como de las garantías para su protección" Constitución Política de los Estados Unidos Mexicanos, DOF 05-02-17.)

De esta forma se sustituye la palabra "garantías" por "derechos humanos", ampliando claramente el catálogo de derechos que ahora sin distinción de clasificación, gozan todos del mismo status, incluyendo también una modificación en el vínculo de las normas internacionales con las nacionales, obligando a los que operan el derecho a usar como herramienta el derecho conjunto de ambas normas y sin jerarquía alguna. Dentro de esta nueva integración al mandato constitucional, los Derechos Económicos, Sociales y Culturales, entraron de lleno a la controversia en cuanto a su justiciabilidad y exigibilidad consolidándose jurídicamente. Esta herramienta integral, fue de gran relevancia para la inclusión de los derechos sociales toda vez que tanto en la constitución como en los medios internacionales se precisa el contenido y las obligaciones que de cada derecho se desprenden. Por ello a pesar de la idea de que los derechos sociales son programáticos y sólo pretenden ser realizables como una promesa a cumplir, cuando se acude a estos medios de uso internacional de los que el Estado mexicano es parte, son claros en detallar tanto en su normativa como en sus observaciones del Comité de Derechos Económicos, Sociales y Culturales, como es que se debe de trabajar en los Estados para cumplirlos.

La justiciabilidad y exigibilidad de los derechos sociales ya no están en duda, existen los medios necesarios que los han consolidado en el mundo jurídico, solo basta la plena interpretación de los mismos y una actualización de paradigma y cultura social para lograrlos, toda vez que dotarlos de estos principios los enriquece en el sistema legal, el cumplimiento no sólo corresponde una obligación del Estado, sino también corresponde un tanto de responsabilidad por parte de los que gozan los derechos, de conocer y utilizar de manera consciente y responsable los mecanismos que lo llevan a él y a la sociedad a un pleno disfrute de los mismos.

En México los mecanismos de cajón para garantizar el derecho a la vivienda son aquellos que ayudan a adquirir una, es decir, son los destinados al acceso, a través de financiamientos 
otorgados principalmente por las instituciones como Infonavit, Fovissste y Subsidios Federales es que puede el mexicano tener acceso a la obtención de una vivienda.

El Infonavit ofrece y otorga soluciones financieras, para que los trabajadores y derecho habientes adquieran una vivienda, esto es muy importante destacar, esta institución, sólo ofrece financiamiento a la clase trabajadora, eso es así, porque nace con ese objetivo en 1972 y si bien, ha modificado mecanismos internos, el sector de población a la que es destinado este Instituto sigue funcionando sólo para los trabajadores.

El Fovissste está encargado de otorgar créditos a los trabajadores que estén propiamente solo al servicio del Estado para adquirir una vivienda. Al igual que el Infonavit, esta institución de financiamiento está dedicada a la clase trabajadora, con la restricción de ser estatal.

Según el Informe Alternativo Conjunto sobre los Derechos Económicos, Sociales, Culturales y Ambientales de Habitat International Coalition, en México "la adquisición de la vivienda nueva sólo es accesible para quienes perciben más de cinco salarios mínimos, ya que a partir de ese nivel de ingreso se puede acceder a créditos hipotecarios públicos y privados" (De, Agrario, \& Urbano, n.d.) Adicionalmente, la Coneval destaca que "aproximadamente 73.6 millones de mexicanos se encuentran prácticamente excluidos del mercado formal de vivienda al no percibir ingresos por hogar equivalentes a más de cinco salarios mínimos" (, 2018a), esto es un grave problema en el tema de la igualdad en el acceso a créditos para adquisición de vivienda, las instituciones más importantes de financiamiento a la vivienda, sólo están dedicadas a un sector de la población, desprotegiendo al otro tanto.

Sin embargo, para el sector de la población que no cuenta con ingresos suficientes o menores a lo posible para adquirir un crédito de vivienda, existen subsidios otorgados por la Comisión Nacional de Vivienda, que si bien, buscan ser un apoyo a los grupos vulnerables con mayor necesidad, estos deben cumplir requisitos como los siguientes, según la Comisión Nacional de Vivienda: Contar con el Registro Único de Población (CURP): no haber recibido un subsidio en períodos fiscales anteriores o presentes, no contar con vivienda propia, percibir ingresos menores o iguales a 11 mil pesos y tener una cuenta de ahorro o una subcuenta de vivienda, entre otros, lo anterior denota que no existe posibilidad de obtener vivienda de manera sencilla y dinámica.

Los mecanismos de adquisición de créditos mostrados, infieren una falta de adaptación, de fortalecimiento y crecimiento en cuanto a la desigualdad que manejan en su funcionamiento, se puede deducir de lo anterior, que no todas las familias e individuos tienen acceso a financiamiento para adquirir viviendas, y cuando así fuere el caso, a la hora de la adquisición, si la vivienda cumple o no, con los elementos necesarios para considerarse digna y decorosa, ya no es competencia de las instituciones financieras la responsabilidad de tal adquisición.

Las viviendas adquiridas principalmente en los últimos años han sido las viviendas de interés social, estas viviendas según la Ley de Vivienda del Estado de Jalisco son aquellas cuyo precio máximo no excede de la cantidad de cinco mil cuatrocientos veinticinco veces el valor diario de la Unidad de Medida y Actualización al término de su edificación, lo cual equivale aproximadamente a cuatrocientos setenta mil pesos. Estas viviendas, si bien, resultan ser de bajo costo y accesible, no tienen las condiciones de lo que se considera una vivienda adecuada, sin embargo, son adquiridas para satisfacer esa necesidad. La creación de estas viviendas debe ser fundamentada en una planeación estratégica tanto del crecimiento urbano como de la población, bajo políticas que logren sus objetivos en base a la problemática existente.

Este tipo de vivienda, suele construirse en las periferias de las ciudades, lo que provoca una rápida expansión de la mancha urbana y evidentemente, una afectación en los traslados de sus habitantes. Un ejemplo claro de la aplicación de políticas públicas o planeación fallida en materia de vivienda, es el municipio de Tlajomulco, Jalisco, ocupando el tercer lugar en el país con el mayor número de viviendas abandonadas, estas construcciones fallidas de casas de interés social provocaron un abandono que padece actualmente este municipio, lo que aunado a este problema inicial, se suman otros como: inseguridad, fraudes, vandalismo, focos de infección, etcétera, se calculan 68,000 viviendas en condiciones de abandono, tan grave el problema es, que la 
Secretaría de Desarrollo Agrario, Territorial y Urbano (SEDATU), el Infonavit y el mismo municipio de Tlajomulco de Zúñiga, trabajarán en conjunto para la recuperación de estas casas, un problema como este, atiende a una decisión incorrecta por parte de alguna política pública adoptada en Jalisco; ante esta situación, ¿quién se hace responsable del resultado de una mala decisión política? En Tlajomulco la afectación es compleja, toda vez que por medio de otra política pública se dará una posible solución, pero no se busca el motivo inicial del problema, en tanto, no hay responsables. Parte de la protección jurídica de los ocupantes de viviendas que no cumplen con las características de dignidad y decoro, debería de ser el llevar a cabo sanciones a los productores, ya sean del sector público o privado.

Es prioridad en México el acceso a la vivienda, antes que cumplir con la dignidad y el decoro de esta, ahora bien, cuando el Estado no llega a cumplir con las obligaciones correspondientes al respeto, protección y práctica tal como lo estipula el artículo primero en relación al cuarto constitucional, cualquier persona que padezca esta situación, debería tener el acceso a uno de los mecanismos de protección jurídica para reivindicar su derecho.

¿Qué hacer cuando se vulnera y se encuentra afectado el derecho a la vivienda? Ya sea individual o de manera colectiva, el acceso a interponer una demanda por vulneración del derecho humano a una vivienda digna y decorosa debe ser posible, para una debida reparación y compensación por ello. En párrafos anteriores, respecto de la justiciabilidad y exigibilidad, se aclaró el porqué del derecho a la vivienda como derecho social es justiciable. Los mecanismos de protección jurídica en materia de vivienda tanto a nivel nacional como internacional son posibles; para iniciar un procedimiento en el cual un individuo lleve a instancias correspondientes para reclamar su violación o posible afectación y vulneración al derecho humano a la vivienda, es indispensable, fundamentar en cuál de sus elementos es que se ve afectado este derecho; como se ha visto el derecho a la vivienda es complejo y su conformación es interdependiente de otros derechos, por lo que, para su reparación, debe ser específico y, en el caso particular, señalar la afectación a la cual se ve proclive la transgresión del derecho. En otras palabras, no existe un mecanismo único de protección del derecho a la vivienda, dada su conformación, es posible asistir a diversos caminos para afrontar su inobservancia. Según Pacheco y Sales (2011), "hay dos modelos de mecanismos de control que se utilizan: 1) los mecanismos de control judicial que toman decisiones vinculantes para los poderes políticos, y 2) los mecanismos de control extrajudiciales".

Dependiendo del caso en particular de la afectación, es que se debe buscar la correcta protección del derecho, cuando la afectación proviene de una autoridad específica del Estado, el primer mecanismo de protección jurídica que tenemos ante ese determinado caso es el recurso que cada autoridad prevé en su correspondiente legislación. Cuando ésta no prevé o se agota este recurso en sede administrativa y no hay una respuesta favorable, el medio por excelencia que contempla una protección de cualquier derecho humano incluido el de la vivienda, es el amparo, el cual "no se reduce a una sola garantía judicial (acción o recurso) para la protección de los derechos constitucionales, sino a una variada gama de procesos judiciales que lo configuran más como un derecho constitucional que como una garantía específica" (Brewer-Carías, 2005), con el amparo puede exigirse la aplicación de los derechos humanos.

"El amparo ha funcionado en nuestro país como una forma de pasar de la simple enunciación de los derechos humanos a una instrumentación procesal para evitar sus violaciones" (Melgarejo, 2010), gran herramienta que desde la reforma del 2011 se dotó de mayores supuestos para su ejercicio.

Como mecanismo extra judicial, en México la Comisión Nacional de Derechos Humanos, es el órgano protector y defensor por excelencia de los derechos humanos, adicionado en el artículo 102 apartado B en 1992, instaurado en rango constitucional. Este organismo recibe quejas en materia de derechos humanos y emite recomendaciones a los responsables de alguna vulneración, la $\mathrm{CNDH}$, también está facultada para presentar acciones de inconstitucionalidad en casos específicos, la cual opera emitiendo recomendaciones y recibiendo quejas, sobre abusos en las garantías de los derechos humanos.

A nivel internacional existe un instrumento de gran importancia, creado especialmente para la protección de los derechos sociales, el 
Protocolo Facultativo del Pacto Internacional de Derechos Económicos, Sociales y Culturales (PF - PIDESC), el cual entró en vigor en el año 2013, este mecanismo funciona por medio de dos instrumentos: el primero de ellos, es el procedimiento de denuncia o comunicación; y el segundo, el procedimiento de investigación.

En el primero, las personas, grupos de personas u organizaciones no gubernamentales, pueden presentar sus denuncias por violación a sus derechos, es decir, acuden presentando una denuncia o bien llamada comunicación, señalando la afectación a su derecho correspondiente por parte del Estado y el protocolo resuelve; ahora bien, en la segunda forma, el procedimiento de investigación, solo permite que personas, grupos de personas $\mathrm{u}$ organizaciones no gubernamentales, presenten ante el Comité pruebas de las violaciones a derecho con características de graves a sistemáticas, con la finalidad de que el mismo Comité inicie su propia investigación.

Este par de instrumentos conforman a nivel internacional una gran oportunidad de hacer valer los DESC, por lo que, analizar su utilización requiere un trabajo individual importante.

El derecho humano a la vivienda es justiciable, la posibilidad de reclamar una violación consumada o no, de este derecho se admite en el ámbito jurídico, toda vez que es un derecho humano y se encuentra consagrado en la Constitución Política de los Estados Unidos Mexicanos; sin embargo, el derecho a la vivienda como derecho compuesto puede reclamarse de diversas formas como bien se ha señalado.

En México, la protección jurídica de la condición del derecho a la vivienda puede observarse en las interpretaciones de la Suprema Corte de Justicia de la Nación, que se ha pronunciado al respecto en diversas ocasiones. En 2014 se dictó una sentencia de amparo directo mediante la ponencia del ministro Jorge Mario Pardo Rebolledo de la Primera Sala de la Corte de Justicia de la Nación, bajo el número de expediente 3516/2013 en la que se realizó un generoso análisis sobre la interpretación de la vivienda, que deja entrever cómo la Suprema Corte distingue este derecho, en fragmentos como el siguiente: "El derecho fundamental a una vivienda digna y decorosa, consagrado en el artículo $4^{\circ}$ de la Constitución Federal, si bien tuvo como origen el deseo de satisfacer una necesidad colectiva, no puede limitarse a ser un derecho exclusivo de quienes son titulares de una vivienda popular, o incluso carecen de ella", la Suprema Corte atiende al principio de igualdad el cual, como se señala a lo largo del artículo, se ve vulnerado en los mecanismos de acceso a la vivienda. Así también en referencia a que una vivienda digna sea para todos, declaró: "el derecho fundamental a la vivienda adecuada, o a una vivienda digna y decorosa, protege a todas las personas, y por lo tanto, no debe ser excluyente" Así da un giro trascendente en la interpretación de este derecho, otorgando la obligación de realizar lo correspondiente para que este derecho sea protegido para todos, sin distinción.

Dentro de la tesis aislada con número de registro 2006171 se encuentra una interpretación de la vivienda digna y decorosa como un derecho fundamental, señalando a la letra, lo siguiente:

\section{DERECHO FUNDAMENTAL A UNA VIVIENDA DIGNA Y DECOROSA. SU CONTENIDO A LA LUZ DE LOS TRATADOS INTERNACIONALES.}

[...] se concluye que el derecho fundamental a una vivienda digna $\mathrm{y}$ decorosa, tiene las siguientes características: (a) debe garantizarse a todas las personas; (b) no debe interpretarse en un sentido restrictivo; (c) para que una vivienda se considere "adecuada" requiere contar con los elementos que garanticen un nivel mínimo de bienestar a quien la habite, esencialmente, una infraestructura básica adecuada, que proteja de la humedad, la lluvia, el viento, así como riesgos estructurales, con instalaciones sanitarias y de aseo, un espacio especial para preparar e ingerir los alimentos, espacio adecuado para el descanso, iluminación y ventilación adecuadas, acceso al agua potable, electricidad, y drenaje; y, (d) los Estados deben adoptar una estrategia nacional de vivienda para alcanzar el objetivo establecido en el pacto internacional de referencia, así como tomar e implementar las medidas legislativas, administrativas, presupuestarias y judiciales adecuadas para la realización plena de dicho derecho, dentro de las cuales está asegurar a la población recursos jurídicos y mecanismos judiciales para que los gobernados puedan reclamar su incumplimiento, cuando las condiciones de las viviendas no sean 
adecuadas o sean insalubres. Así, dichos aspectos constituyen los elementos básicos del derecho a una vivienda digna y decorosa reconocido por el artículo 4o., párrafo séptimo, de la Constitución Política de los Estados Unidos Mexicanos, consistente en que todas las personas cuenten con una vivienda que tenga los elementos mínimos necesarios para ser considerada como tal.

Lo anterior muestra una clara explicación de la conformación del derecho a la vivienda, contemplando elementos que deben ser aplicados en el Estado mexicano como responsabilidad para la protección de este derecho. Otra tesis aislada que analiza esta materia a la luz de una interpretación internacional es la emitida por el Primer Tribunal Colegiado en Materia Administrativa del Sexto Circuito con número de registro 2000085, la cual apoyada en el principio pro-homine otorga a la vivienda la obligación de buscar el mayor beneficio de las personas, señalando a la letra:

“DERECHOS HUMANOS. EL RELATIVO A UNA VIVIENDA DIGNA Y DECOROSA DEBE SER ANALIZADO A LA LUZ DE LOS PRINCIPIOS PLASMADOS EN LA CONSTITUCIÓN FEDERAL Y TRATADOS INTERNACIONALES, A PARTIR DE UNA INTERPRETACIÓN MÁS AMPLIA QUE FAVOREZCA EN TODO MOMENTO A LAS PERSONAS (APLICACIÓN DEL ARTÍCULO 10., PÁRRAFO SEGUNDO, CONSTITUCIONAL -PRINCIPIO PRO HOMINE-)" concordancia con el principio pro homine conforme al cual la interpretación jurídica siempre debe buscar el mayor beneficio para el hombre, al examinarse el cumplimiento del objeto de la causa de utilidad pública de una expropiación, consistente en la construcción de viviendas, es menester ponderar el derecho humano de los pobladores del área expropiada a la vivienda digna, a la seguridad social y a una mejora continua de las condiciones de existencia, lo que se logra, a guisa de ejemplo, con la instalación de clínicas de seguridad social y con zonas de reserva natural, al tratarse de elementos que el Estado debe garantizar al proporcionar una vivienda libre de riesgos. Por ello, si con motivo de un decreto expropiatorio quedó un remanente de terreno que no se destinó a la construcción de viviendas, no puede soslayarse que si el excedente se ocupó en elementos estrechamente vinculados con el objeto directo de la causa de utilidad pública, se buscó cuidar de la integridad de los habitantes de la zona expropiada, lo anterior a fin de garantizar la tutela del derecho humano a una vivienda digna y decorosa, a la protección de la salud y a un medio ambiente adecuado para el desarrollo y bienestar de los beneficiados; es decir, el concepto del cumplimiento del objeto de la causa de utilidad pública no puede reducirse en tan sólo la edificación de las viviendas en un sentido estrictamente material, en cambio, una interpretación no restrictiva -atendiendo al principio pro homine- permite acudir a una interpretación del concepto de vivienda acorde con los principios sustentados en la Carta Magna y en los derechos humanos contenidos en el tratado internacional referido, a partir de una interpretación que favorezca en todo tiempo a las personas la protección más amplia.

El concepto de vivienda adecuada a nivel nacional e internacional marca una aseveración de un derecho compuesto. La interpretación depende en demasía del énfasis que el mismo estado le da a este derecho humano fundamental. Desde el punto de partida de las políticas públicas que establece el estado mexicano, se reconoce por los operadores jurídicos, académicos y políticos, que la reforma en derechos humanos de la Constitución Política de los Estados Unidos Mexicanos de 2011 ha tenido gran impacto especialmente en los derechos de segunda generación. Para empezar un desglose del artículo donde se enuncia el derecho a la vivienda, se menciona el derecho al "disfrute", palabra que se traduce en una capacidad de goce respecto un espacio determinado, por lo que la propiedad que sea destinada para esos fines debe de tener ciertos aspectos que sostengan los supuestos de lo que es la vivienda con "dignidad y decoro", en este tenor, la Suprema Corte de Justicia de la Nación. en la tesis "Derecho fundamental a una vivienda digna y decorosa. Su contenido no se agota con la infraestructura básica adecuada de aquélla, sino que debe de comprender el acceso a los servicios públicos básicos" del año 2015, sostiene respecto de la dignidad en la vivienda lo siguiente:

[... si el Estado condiciona el apoyo a la vivienda a que se resida en un lugar determinado, bajo la consideración de que lo 
hace con la finalidad de satisfacer el derecho fundamental a la vivienda digna y decorosa de los gobernados, la vivienda que otorgue debe cumplir no sólo con una infraestructura básica adecuada, sino también con acceso a los servicios públicos básicos, incluyendo el de seguridad pública ya que, en caso contrario, el Estado no estará cumpliendo con su obligación de proporcionar las condiciones para obtener una vivienda adecuada a sus gobernados (Semanario Judicial de la Federación - Tesis 2009348, n.d.);

en esta muy precisa alusión también se engloban "los instrumentos y el apoyo" para lograr cumplimentar este derecho, lo que advierte una específica actuación de las autoridades respecto al tratamiento de este precepto, por lo que el artículo primero constitucional entra de manera directa a formar parte de este derecho por la obligatoriedad y exigibilidad que conlleva. Esto puede concluir en un avance por parte de la interpretación de este órgano, en la cual se ha trabajado por enaltecer los conceptos de la vivienda vinculado a concepciones internacionales; por lo que, si bien el estado mexicano tiene consciencia de lo anterior, en la praxis de la protección jurídica existen múltiples dificultades para su concreta aplicación.

\section{INEFICACIA DEL ESTADO DE DERECHO PARA GARANTIZAR EL DERECHO A LA VIVIENDA DIGNA Y DECOROSA}

Los derechos humanos conforme a sus principios fundamentales son inalienables, no discriminatorios, universales, interdependientes, indivisibles y progresivos, esta última característica es de valor particular para el derecho a la vivienda, el principio de progresividad consiste en:

Una obligación del Estado para asegurar el progreso en el desarrollo constructivo de los derechos humanos, al mismo tiempo, implica una prohibición para el Estado respecto a cualquier retroceso de los derechos. El Estado debe proveer las condiciones más óptimas de disfrute de los derechos y no disminuir ese nivel logrado" ( Comisión Nacional de los Derechos Humanos - México, n.d.).

El avance de lo que se realice en cuestión de derechos humanos debe todo el tiempo mejorar, un retroceso, no conformaría un estado de derecho, toda vez que se vulneraría una de las características básicas de los derechos humanos, el Estado debe buscar prosperidad y avance en esta materia.

En cuanto al derecho a la vivienda, estos años con la implementación del nuevo paradigma en cuestión de derechos humanos, no ha sido notable un cambio positivo; en el año actual y con las incontables herramientas para llevar a cabo el cumplimiento de los derechos, en México no se logra concretar un progreso significativo propio de un desarrollo en el sistema jurídico y mucho menos un cambio cultural.

Para mantener el derecho a la vivienda digna y decorosa, México se enfoca principalmente en el financiamiento, sin embargo, es necesario atender otros derechos interdependientes, como lo son, el derecho al agua, a espacios de recreación, a la felicidad, al mínimo vital, entre muchos más; a falta de éstos en la vida de un ser humano se maneja una calidad de vida no adecuada.

La característica principal del derecho a la vivienda es enaltecer la calidad de vida de los seres humanos, este es el espacio privilegiado de la intimidad de un individuo, ahí donde habita, es capaz de desarrollar su vida personal y familiar, su educación, también es donde se permite estar y ser libre, todo lo que vive, experimenta, siente y desarrolla ahí, es en consecuencia extendido de manera indirecta hacia la sociedad en la que se desenvuelve. En su alrededor más próximo, que pertenece al lugar donde vive, una persona se forja cierto carácter y postura frente a las acciones del gobierno, toda vez que lo que ocurre frente a ese espacio vital, o alrededores, se sabe son resultado de decisiones que emanan de instituciones pertenecientes al Estado. Todas las personas difieren en pensamiento y razón, y cada uno mantiene lazos prioritarios hacia ciertos aspectos de la vida, eso es muy subjetivo en cada persona, según la teoría de las necesidades en la Pirámide de Maslow (2013) la vivienda se sitúa en el segundo bloque de importancia para el ser humano, en el plano de necesidades de seguridad, pero puede ser muy discutible según el estilo de vida, educación y hasta cultura de cada persona.

Maslow identificó cinco niveles distintos de necesidades, dispuestos en una estructura piramidal, en la que las necesidades básicas se encuentran debajo, y las superiores o racionales arriba. (Fisiológicas, seguridad, 
sociales, estima, autorrealización). Para Maslow, estas categorías de relaciones se sitúan de forma jerárquica, de tal modo que una de las necesidades sólo se activa después que el nivel inferior está satisfecho. Únicamente cuando la persona logra satisfacer las necesidades inferiores, entran gradualmente las necesidades superiores y con esto la motivación para poder satisfacerlas (Golovina \& Valle, 2013, p. 7).

Esto aplicado en el catálogo de derechos humanos existentes, tiene una gran importancia para su satisfacción, si bien, estos no son graduales, suelen ser interdependientes y tuvieran que ser todos cumplimentados para su debida realización entre sí.

El Estado entonces tiene una obligación con el gobernado de brindarle una vivienda digna y decorosa. Esta obligación no refiere un mero espacio físico, es un conjunto de elementos que conforman este derecho humano fundamental, que, si bien ha tenido un largo recorrido por la legislación para ser exigible, no le quita la justiciabilidad y exigibilidad que requiere para su cumplimiento. La legislación nacional e internacional conceptualiza a la vivienda como un conjunto de elementos necesarios, básicos y adecuados para la subsistencia humana, abarcando tanto su existencia, como la misma conservación de la vida. Que el Estado no cumplimente con este derecho y su debida aplicación, conforme a las disposiciones vigentes de la materia, quebranta un estado de derecho y este es un problema grave que se debe erradicar.

Estamos ante un problema jurídico que alude a la falta de atención por parte del Estado respecto a la vivienda, por sus ineficaces planes de acción, su incumplimiento tanto como por acciones desacertadas y sus omisiones en relación con la normativa vigente.

La capacidad económica del Estado es un problema que impide garantizar este derecho, si no se cuenta con las herramientas para tratarlo ¿cómo es que se hace exigible? ¿dónde debe recaer la responsabilidad para pretender un estado de derecho el cual no cuenta con el presupuesto necesario para la garantía de este derecho humano fundamental?
La pobreza en México es una afectación que ha sido sobresaliente durante mucho tiempo, en México ser pobre según el Coneval, es cuando se tiene una carencia de alguno de los seis indicadores $\mathrm{y}$, cuando su ingreso es insuficiente; los indicadores a los que hace referencia esta concepción de la pobreza están determinado por el artículo 36 de la Ley General de Desarrollo Social (2004):

I. Ingreso corriente per cápita;

II. Rezago educativo promedio en el hogar;

III. Acceso a los servicios de salud;

IV. Acceso a la seguridad social;

V. Calidad y espacios de la vivienda digna y decorosa;

VI. Acceso a los servicios básicos en la vivienda digna y decorosa;

VII. Acceso a la alimentación nutritiva y de calidad;

VIII. Grado de cohesión social, y

IX. Grado de Accesibilidad a carretera pavimentada

Estos rubros funcionan para realizar la identificación y la medición de la pobreza en México, del análisis de los nueve componentes, tres, están estrechamente relacionados con la vivienda, de ahí, emana la importancia que la vivienda acarrea para la dignidad humana, el bienestar y el desarrollo de otros derechos. Estos lineamientos utilizan a la vivienda y sus elementos, como factor para determinar la pobreza, es decir, las condiciones de la vivienda pueden establecer el grado de pobreza en el país, no puede entonces liberarse la idea de la trascendencia que conlleva la vivienda dentro de la delimitación de pobreza en México, las fracciones IV, V y VI señalan probablemente las de mayor relación con la vivienda, pero existe una interdependencia de la totalidad de los lineamientos; ahora bien, la fracción IV referente al acceso de la seguridad social, es el lineamiento del cual el $71 \%$ de las personas carece, según estadísticas del Coneval (2018); el acceso a la seguridad social en materia de vivienda, se 
traduce al acceso de la vivienda, en cuanto a sus mecanismos, desde el acceso a créditos para la obtención de una vivienda o construcción, hasta la exigibilidad de este derecho frente al Estado; ahora bien, respecto de la fracción $V$ que señala la calidad y espacios de la vivienda digna y decorosa, el $13.8 \%$ de personas en México (Coneval, 2018) carecen de estos fundamentos, interpretado como las características y elementos que constituyen una vivienda; y por último la fracción VI sobre los accesos a los servicios básicos en la vivienda digna y decorosa, con afectación del $24.7 \%$ de personas (Coneval, 2018).

El análisis de lo anterior deja claro que gran porcentaje de los mexicanos no cuenta con una vivienda digna y decorosa, por lo que conforme a lo que representa este derecho en su carácter social no está plasmado un resultado que pueda aterrizar en un cumplimiento por parte del Estado, toda vez que, si bien no hay cumplimiento total, tampoco existe un progreso con el paso de los años que esté logrando un cambio y una dura implementación de los nuevos conceptos y adaptaciones para tutelar este derecho.

En el ámbito internacional desde septiembre del año 2000 la Asamblea General de la Organización de las Naciones Unidas (ONU), aprobó la Declaración del Milenio, la cual desarrolló los Objetivos de Desarrollo del Milenio (ODM), con la intención clara de marcar un parteaguas hacia un cambio radical en el mundo, determinando como plazo 15 años para trabajar en ellos y consolidarlos; entre los países miembros se mantuvo un compromiso, de adoptar estos objetivos, los cuales deberían de tratar establecer en sus planes de Estado, las estrategias necesarias para lograr los objetivos.

En la Cumbre de las Naciones Unidas sobre el Desarrollo Sostenible, en la sede de la ONU en Nueva York, en el año 2015, se aprobó la Agenda 2030 para el Desarrollo Sostenible, bajo la unión de 193 países entre ellos México, se concluyó un proceso de negociaciones intergubernamentales, que incluían la participación de la sociedad civil, informes, revisión de programas, etcétera, la cual tuvo una duración de dos años. El documento final cuenta con un programa conformado por 17 Objetivos de Desarrollo Sostenible (ODS) que incluyen 169 metas y reemplazan a los Objetivos de Desarrollo del Milenio (ODM), que expiraron al final del año 2015. Esta nueva agenda entró en vigor en enero del 2016 y tiene como meta cumplirse hasta el año 2030.

La Agenda 2030 de Desarrollo Sostenible es un plan de acción, una nueva estrategia que regirá los programas de desarrollo mundiales los próximos 15 años, es un plan a favor de las personas, el planeta y la prosperidad, que también tiene la intención de fortalecer la paz mundial y el acceso a la justicia.

Estamos resueltos a poner fin a la pobreza y el hambre en todo el mundo de aquí a 2030, a combatir las desigualdades dentro de los países y entre ellos, a construir sociedades pacíficas, justas e inclusivas, a proteger los derechos humanos y promover la igualdad entre los géneros $y$ el empoderamiento de las mujeres y las niñas, y a garantizar una protección duradera del planeta y sus recursos naturales (ONU, 2015), señalaron los Estados en la resolución.

En el caso que nos ocupa, el Objetivo de Desarrollo Sostenible número 11, señala "lograr ciudades y comunidades sostenibles", es de mera importancia para analizar a futuro lo que podría ser la vivienda, si bien, todos están interrelacionados, el que más abarca las necesidades de una vivienda adecuada es este objetivo. México debe trabajar a la par con estos objetivos y pretender cumplir con éstos, debe de haber un cambio de paradigma, estos objetivos tienen un propósito certero: es posible, con el trabajo en conjunto, mejorar la existencia para todos en el mundo. Y cabe la importancia total de lo que representa la vivienda para este fin. Lograr la sostenibilidad, no es un proceso fácil, pero con las obligaciones de los Estados, las responsabilidades de cada uno de los seres gobernados, un cambio social podría ocurrir.

En México, existen problemas de todo tipo en materia de vivienda, el principal factor que provoca estos problemas, aquel que padece la sociedad, es la situación de pobreza en la que se encuentran millones de mexicanos.

Como grupo vulnerable, las acciones que se tomen en México respecto a la vivienda deberían de ser enfocadas a su desarrollo, el objetivo del desarrollo sostenible número once, está dedicado a lograr ciudades y comunidades sostenibles, lo que lo acerca al aspecto de la vivienda, más que a 
cualquier otro, por eso es que se ha de analizar las líneas de acción para contribuir al cumplimiento de este objetivo y adaptarlas a las acciones en México.

Como principales líneas de acción, la Organización de las Naciones Unidas (2015) señala que se debe favorecer la adquisición de la vivienda a las personas en situación de pobreza, mediante financiamientos con tasas preferenciales e impulsar la promoción y construcción vertical, asimismo, se debe buscar el cuidado con el uso del suelo, fortalecer los programas de desarrollo urbano y evitar la densificación del tejido urbano ya consolidado, incentivar la construcción de la vivienda de manera positiva y capacitar a las autoridades correspondientes de planificación y gestión de vivienda para que exploten de manera positiva el desarrollo de la vivienda, que conlleve el mayor beneficio para los habitantes; dentro de las líneas de acción también se propone realizar estrategias que logren la integración de la población vulnerable, controlar el rezago mediante la atención a la infraestructura de zonas rurales e indígenas, mejorar los programas de desarrollo económico y financiamientos para adecuar a las necesidades específicas de toda la población y también, fortalecer programas de atención a la vivienda para mejoramiento y ampliación frente a los de adquisición.

Estas medidas de la ONU, pretenden lograr un mejoramiento en materia de vivienda, por lo que la adaptación al sistema mexicano, como una actualización, resulta totalmente necesaria, si bien, los ODS no tienen obligatoriedad jurídica, sin embargo, cuentan con una promesa por cada Estado parte a realizarse, son una herramienta para la consolidación en diversas materias en el mundo; en México, debería de ser un modelo a seguir y formalizarse adaptando lo necesario para funcionar eficazmente, porque lo necesita, la vivienda en México exige una cambio radical desde la percepción que se tiene de la misma, hasta todo un cambio en su sistema e instituciones, México no debería quedarse atrás en la implementación de un desarrollo sostenible.

\section{CONCLUSIONES}

El ser humano necesita un cambio de paradigma, en cuanto a la percepción de los derechos y de sí mismo, los sistemas jurídicos $\mathrm{y}$ sociales deben proteger y resguardar esencialmente la dignidad humana. Los derechos que conforman la vida de cualquier individuo conservan el propósito de lograr su bienestar, así como su seguridad personal. Desde que el hombre nace y hasta que muere goza de un conjunto de derechos y obligaciones específicas inherentes que le permiten un desarrollo integral y ordenado en la vida.

La vivienda conforma el hogar de cada ser humano, es términos vagos un lugar "sagrado", ahí se lleva a cabo el desarrollo humano, físico, espiritual y mental de los individuos, y da pie al desarrollo en sociedad. Todo lo que pasa alrededor de una vivienda, todo lo que el Estado hace mal o hace bien tiene afectaciones en dicho entorno y por lo tanto se resiente en sentido individual.

El derecho humano a la vivienda digna $y$ decorosa tiene la finalidad de dotar a los seres humanos de un espacio que responde al conjunto de elementos básicos para subsistir, va más allá de brindar una casa o una infraestructura donde vivir, el sentido de ese espacio debe conformarse por características específicas contenidas en la normativa nacional e internacional, así como en los diversos sitios de estudio e interpretación.

Si bien el derecho a la vivienda cuenta con las peculiaridades de un derecho social, es un derecho para todos, sin distinción y excepciones en su ejercicio y aplicación. El estado mexicano trabaja con un sistema específico utilizado en materia de vivienda, constituido por instituciones y normativas que parten del marco constitucional establecido en el artículo 4, párrafo séptimo de la Carta Magna. De su análisis se desprendió, a lo largo del presente artículo, que el estado mexicano para llevar a cabo la garantía al derecho a la vivienda centra y dedica sus esfuerzos y recursos, principalmente a las instituciones dedicadas a los mecanismos de acceso a la vivienda, sin embargo, estos no cumplen con el principio de igualdad, restringiendo oportunidades y brindando financiamientos a la clase trabajadora formal.

En cuanto a los mecanismos de protección jurídica se cuenta con instrumentos factibles para la garantía de este derecho, sin embargo, no existe una herramienta única para hacerlo exigible, las peculiaridades que lo conforman lo hacen un derecho complejo y de múltiples ejercicios para su configuración, por lo que estos mecanismos dependen de una competencia específica, no obstante, las autoridades correspondientes tienen una responsabilidad de lograr restaurar en sus 
competencias la vulnerabilidad y violación de este derecho, así como el poder de sancionar lo indebido.

Definitivamente se tienen los instrumentos para trabajar en base a un paradigma distinto, sin embargo, en el sistema jurídico actual no se ha consagrado así. Es importante afrontar la realidad de un desgaste que se ha ido forjando con los años, debe México, hacer un enfoque a futuro, donde mediante un panorama más amplio y abierto al que se tiene, se pueda trabajar con todas las herramientas existentes internacionalmente, es hora de también aplicar los medios de protección jurídica acompañados de bases teóricas que se tienen, y utilizarlos de manera adecuada.

El cumplimiento del derecho a la vivienda, en tanto las obligaciones del Estado de respetar, proteger, realizar y garantizar este derecho, debe hacerlo en su totalidad, lograr la eficacia, no postergarla, asimismo los gobernados, los receptores de las prerrogativas del Estado, deberían también de respetar, proteger, realizar y garantizar sus propios beneficios, pero sobre todo conocer e informarse sobre lo que ocurre y tratar de contribuir a la sociedad para un bienestar propio y social.

Los mecanismos del derecho humano a la vivienda funcionan a medias, con el presupuesto inconstante e instituciones débiles que no trabajan con programas y planes que logren un auge verdadero en el cumplimiento de los mecanismos, se tiene como consecuencia, programas que apoyan a la mitad de las personas que debería, planes de desarrollo urbano que no se respetan y se impugnan, grupos vulnerables que no se favorecen prioritariamente con financiamientos especiales, construcción de viviendas en zonas no habitables, etcétera. Este cúmulo de problemas se hace más grande cada día.

No se trabaja como debería, los procedimientos llevados a cabo, no llevan a la eficacia de la norma establecida en materia de vivienda, las instituciones dedicadas a eso, no llevan a cabo acciones contundentes y tampoco en sintonía con los instrumentos internacionales, por lo que, si bien existe la normativa, pero no el cumplimiento total, entonces sólo se posterga la eficacia, no hay progresividad notable que diferencie lo que hubo hace diez años a lo que actualmente existe.
Esto implica una situación grave, si no hay eficacia de la norma constitucional, el Estado de Derecho se ve afectado dentro del sistema jurídico, porque aun cuando existan los enunciados que contengan las normas, al ser cumplidas a medias, debería de existir una responsabilidad por parte del Estado. Si el Estado no cumple no pasa nada, las normas no son eficaces, pero no pasa nada, al comparar el marco normativo con la realidad, en este sentido, podemos constatar que no hay herramientas necesarias para producir mayores beneficios y hacer cumplir totalmente con el derecho a la "vivienda digna y decorosa".

El Estado debe recordar que su obligación es velar por el cumplimiento de lo estipulado en la Constitución, y con los recursos que maneja, buscar las fórmulas adecuadas para progresar en el avance de los derechos humanos de todos, el contenido de la Constitución debe ser inviolable, y si es así, los mecanismos de protección jurídica deben conformar con justicia y legalidad en el marco de la Constitución e instrumentos internacionales, cada condición específica de la realidad.

El sistema conformado por instituciones, mecanismos y normativa dedicadas en materia de vivienda tiene que ser sustituidos. Dentro de las instituciones los recursos públicos destinados a este sector deben de ser asignados a trabajar específicamente en la promoción y dignificación en la producción de viviendas.

En cuanto a los mecanismos de acceso a la vivienda se debe incorporar un nuevo sistema que permita mayores facilidades en la obtención de viviendas, tasas accesibles, así como mejoras en la construcción de los créditos que se otorgan. En un sentido más amplio, se debe romper ese nexo a la desigualdad que sólo permite a los trabajadores esta disposición e incorporar en el sistema de financiamientos acceso para todos.

De la protección jurídica que el derecho humano a la vivienda goza es necesario que el Poder Judicial refuerce criterios para la obtención de resultados satisfactorios en un marco general, es decir, las resoluciones que emiten deben tener armonía con lo estipulado en la normativa nacional e internacional enfocado en las necesidades específicas, así como la integración de sanciones sólidas a los responsables de la vulneración de este derecho. En este tenor, al 
análisis de los fallos pertinentes es necesario que el Estado logre adoptar políticas públicas para la erradicación de la problemática que se enfrenta a diario en México.

La interpretación del derecho a la vivienda a la luz de las normas internacionales es muy amplia, por lo que debe de entenderse que la aplicación y ejecución de lo estipulado en esos medios, no sólo pertenece al Estado, sino también al sector privado que igualmente se encarga de producción y mercadeo, asimismo, deben de imponerse medidas relacionadas con qué mínimo de espacio y servicios se deben de crear viviendas, así como límites y en su caso sanciones por vulneración del derecho a la vivienda.

El derecho a la vivienda está descuidado, es necesario llevar a cabo acciones en todos los Poderes y niveles del Estado, hechos en conjunto con la atención necesaria en todos los ámbitos y mecanismos de protección pueden forjar a futuro un proyecto solemne que dignifique la vivienda en México.

\section{BIBLIOGRAFÍA}

- Abramovich, V., \& Courtis, C. (1997). "Hacia la exigibilidad de los derechos económicos, sociales y culturales. Estándares internacionales y criterios de aplicación ante los tribunales locales". Tratados Sobre Derechos Humanos Por Los Tribunales Locales. Buenos Aires: Editores del Puerto, pp. 283-350.

- ACNUDH. (n.d.). ¿Cuáles son las obligaciones de los Estados respecto de los derechos económicos, sociales y culturales?. Disponible en https://www. ohchr.org/SP/Issues/ESCR/Pages/What aretheobligationsofStatesonESCR.aspx

- Antonio Cruz Parcero, J. (2017). Reflexiones sobre derechos sociales $y$ desigualdad. Disponible en https://goo. $\mathrm{gl} / \mathrm{pZiZhn}$

- Brewer-Carías, A. R. (2005). Mecanismos Nacionales de Protección de los Derechos Humanos. San José de Costa Rica: Instituto Interamericano de Derechos Humanos.

- Castañeda, M. (2016). Los principios de universalidad, interdependencia, indivisibilidad y progresividad de los Derechos Humanos. Ciudad de México: Comisión Nacional de los Derechos Humanos CNDH.

- CONEVAl. (2018). Pobreza 2018. Disponible en https://www.coneval. org.mx / Medicion / M P / Paginas / Pobreza-2018.aspx
- Constitución Política

de los Estados Unidos Mexicanos. (n.d.). Disponible en https://doi.org/10.29057/ icea.v4i7.201

- Cossío Díaz, J. R. (2016). "Problemas para la exigibilidad de los derechos sociales en México". En: Formación y perspectivas del Estado en México. Fix-Zamudio, H., y Valadés D. (Coords.)., pp.: 127-149. Disponible en http://ru.juridicas.unam. $\mathrm{mx} / \mathrm{xmlui} /$ handle/123456789/11781

- Cossío Díaz, J. (s.f.). Los derechos sociales como normas programáticas y la comprensión política de la Constitución. México. Disponible en http://ru.juridicas.unam.mx/xmlui/ handle/123456789/14912

- Cruz Parcero, J. A. (2017). "Historia y porvenir de los derechos sociales en México". Revista del Centro de Estudios Constitucionales.5. (julio-diciembre) pp.: 35-68.

- Da Silva, J. A. (2003). "Normas constitucionlas de eficacia limitada". En: Aplicabilidad de las normas constitucionales. México. Universidad Autónoma de México, pp.: 103-154.

- Derechos económicos, sociales y culturales (DESC). Organización de las Naciones Unidas para la Educación, la Ciencia y la Cultura. (n.d.). Disponible en http://www.unesco.org/new/es/ 
social-and-human-sciences/themes/ advancement/networks / larno / economic-social-and-cultural-rights/

- Diario Oficial de la Federación. (07/02/1983).

- Golovina, N. S., \& Valle, E. L. M. (2013). "Teorías motivacionales desde la perspectiva de comportamiento del consumidor". Negotium, 9(26): 5-18. Disponible en https://doi.org/10.1016/j. cya.2016.03.001

- Hierro, L. (2003). La Eficacia de las Normas Jurídicas. Barcelona: Ariel. Ley General de Desarrollo Social. (2004). Diario Oficial de La Federación. Disponible en http://www. diputados.gob.mx/LeyesBiblio/pdf/264. pdf

- Melo de Moraes R., N. (2014). La Contribución del Poder Judicial a la Protección de los Derechos Humanos de la Tercera Generación; Especial Referencia al Derecho al Desarrollo. Salamanca: Universidad de Salamanca.

- Melgarejo, R. B. (n.d.). Colección sobre la protección constitucional de los derechos humanos. Fascículo 2. Control jurisdiccional y protección de los derechos humanos en México.
- ONU. (2015). La Asamblea General adopta la Agenda 2030 para el Desarrollo Sostenible. Disponible en https://news. un.org/es/story/2015/09/1340191

- ONU (Organización de las Naciones Unidas). (1966). Pacto Internacional de Derechos Económicos, Sociales y Culturales. Pacto Internacional de Derechos Económicos, Sociales y Culturales, pp. 1-7. Disponible en https://doi.org/10.1017/ CB09781107415324.004

- ONU (Organización de Naciones Unidas). (1966). Pacto Internacional de Derechos Civiles y Políticos. 45271(C), 1-16. Disponible en https://doi.org/10.1017/ CB09781107415324.004

- Comisión Nacional de los Derechos Humanos - México. (n.d.). (2015). ¿Qué son los derechos humanos? Disponible en https://www.cndh.org.mx/derechoshumanos / que-son-los-derechoshumanosRivadeneira, R. A. Derechos sociales. Vol. 2. Disponible en http:// biblio.juridicas.unam.mx/libros/libro. htm?l=3796

- Vicente Giménez, T.(2006). La Exigibilidad de los Derechos Sociales. Valencia: Tirant Lo Blanch. 